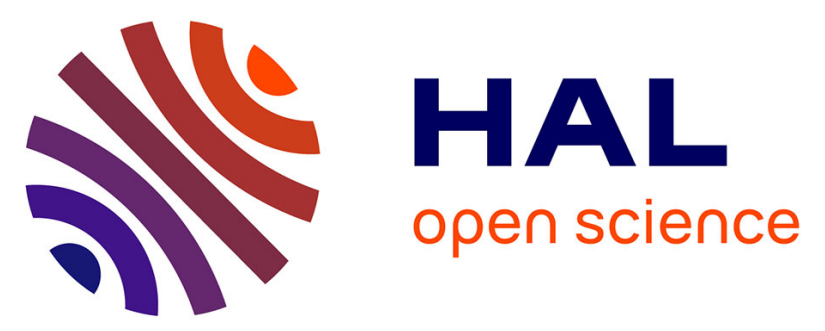

\title{
Letter to the Editor Regarding "Adjunctive Gamma Knife Surgery or Wait and Scan Policy After Optimal Resection of Large Vestibular Schwannomas: Clinical and Radiologic Outcomes"
}

Constantin Tuleasca, Roy Thomas Daniel, Daniele Starnoni, Mercy George, Raphael Maire, Marc Levivier

\section{To cite this version:}

Constantin Tuleasca, Roy Thomas Daniel, Daniele Starnoni, Mercy George, Raphael Maire, et al.. Letter to the Editor Regarding "Adjunctive Gamma Knife Surgery or Wait and Scan Policy After Optimal Resection of Large Vestibular Schwannomas: Clinical and Radiologic Outcomes". World Neurosurgery, 2019, 122, pp.719-721. 10.1016/j.wneu.2018.10.038 . hal-02179230

\section{HAL Id: hal-02179230 \\ https://hal.sorbonne-universite.fr/hal-02179230}

Submitted on 10 Jul 2019

HAL is a multi-disciplinary open access archive for the deposit and dissemination of scientific research documents, whether they are published or not. The documents may come from teaching and research institutions in France or abroad, or from public or private research centers.
L'archive ouverte pluridisciplinaire HAL, est destinée au dépôt et à la diffusion de documents scientifiques de niveau recherche, publiés ou non, émanant des établissements d'enseignement et de recherche français ou étrangers, des laboratoires publics ou privés. 


\section{Letter to the editor regarding}

“Adjunctive Gamma-Knife surgery or wait \& scan policy after optimal resection of large vestibular schwannomas: clinical and radiological outcomes"

Constantin Tuleasca ${ }^{1,234}$, MD-PhD, Roy Thomas Daniel' ${ }^{12}$, MBBS, MCh, Daniele Starnoni', MD, Mercy Georges, MD, Raphael Maires, MD, Marc Levivier ${ }^{1^{2}}$, MD, PhD, IFAANS

Department of Clinical Neurosciences, Neurosurgery Service and Gamma Knife Center, Lausanne University Hospital, ${ }^{2}$ University of Lausanne, Faculty of Biology and Medicine (FBM), ${ }^{3}$ Signal Processing Laboratory (LTS 5), Ecole Polytechnique Fédérale de Lausanne (EPFL), 'Sorbonne Université, Faculté de Médecine, ${ }^{5}$ Department of Otorhinolaryngology, Head \& Neck Surgery, Lausanne University Hospital, Switzerland

\section{Corresponding author:}

Constantin Tuleasca, $\mathrm{MD}-\mathrm{PhD}$

Lausanne University Hospital (CHUV), Neurosurgery Service and Gamma Knife Center, Rue du Bugnon 46, CH-1011, Lausanne, Switzerland;

Tel.: + 417955623 43; Fax: + 412131411 99; e-mail: constantin.tuleasca@ gmail.com

Acknowledgment: Lausanne University Hospital

Conflict of interest: none 
Dear Sir,

We read with great interest the recent article by Troude et al. ${ }^{1}$ with regards to adjunctive Gamma Knife surgery (GKS) after planned subtotal resection of large vestibular schwannomas. Overall, 27 patients (19\%) presented with growing residues. The local progression free survival (LPS) was not statistically different (up to seven years of postoperative follow-up) between the wait and re-scan group as compared with the upfront GKS group. The authors concluded that the low probability of long-term regrowth of small remnant tumors is an argument for a wait and re-scan protocol.

However, several aspects warrant further analysis. Firstly, this was not a randomized controlled trial, so as to be able to conclude, providing level I evidence, that observation with further scanning should be performed for residual tumors after microsurgery. Furthermore, the allocation of the observation group based upon older age, smaller remnants and postoperative facial nerve deficit induces further selection biases. Moreover, only less than half $(41 \%)$ of the patients were scanned for more than 5 years. The authors found no statistically significant correlation between the volume of the residual tumor and further regrowth. Secondly, the "functional sparing surgery" as the authors nicely call it, might involve different strategy of tumor resection and lead to different degrees of preservation of the facial and cochlear nerve, as recently reviewed by our group ${ }^{2}$. Troude et al. report $84 \%$ of patients with House-Brackmann (HB) grade I or II facial function postoperatively ${ }^{1}$. Here, it would have been important to underline how many patients had no facial weakness at all (thus reporting separately HB grade I). Regarding the cochlear nerve preservation, from those having had serviceable hearing preoperatively, only $10 \%$ retained it. Thirdly, defining remnant tumor growth as more than $20 \%$ increase as compared to the first postoperative MRI is a choice that is not a gold standard in the current literature. Moreover and in the same sense, clinical assessment should remain mandatory and part of the decision-making process in these former cases. Fourthly, including type II neurofibromatosis cases $(n=19,6 \%)$ in the analysis, with their different pathophysiological profiles, might also have induced further bias in the analysis. Lastly, some histological aspects might be of further interest and explain tumor regrowth after microsurgery, as Iannella et al recently reported ${ }^{3}$. In fact, patients with higher Ki-67 index might have higher tumor regrowth rates $^{3}$. The former induces an additional debate, as it suggest that age, tumor remnant or neurological function are just a glimpse of the decision-making, and do not cover all the aspects.

The authors cite our previous study on combined approach with subtotal removal followed by GKS in large $\mathrm{VS}^{4}$, and quote that LPS actuarial control rate was $77 \%$ at 2.6 years 
and further remained stable during time. However, in our series, only 3 patients (corresponding to a crude rate 9.4\%) had continuous tumor growth. This aspect is important to underline, as in the series of Troude et al. ${ }^{1}$, as in all the published series that they have reviewed on the same topic, LPS is reported as crude rates and not as actuarial ones. Thus, comparatively, the LPS reported by our group was $91.6 \%$ and not $77.7 \%{ }^{4}$. In the same series, we have described our "nerve-centered approach", aiming to improve the patient's functional outcome, and report no facial palsy (100\% House-Brackman grade I postoperatively), with additionally $94.1 \%$ of patients retaining serviceable hearing, if they had serviceable hearing before surgery ${ }^{4}$.

Planned subtotal resection followed by GKS has emerged as a paradigm shift and few series have, up-to-date, published their results with this approach. In our recent metaanalysis $^{2}$, it has been underlined that overall HB grade I-II was achieved in $96.1 \%$ of patients (95\% CI 93.7\%-98.5\%), while serviceable hearing was maintained in 59.9\% (95\% CI 36.5\%83.2\%). A comprehensive review on the published data can be found in table 1. It includes an update of our own series (46 patients with a mean follow-up of 36.9 months), confirming the high level of functional preservation (100\% HB I, $82.3 \%$ of serviceable hearing, when serviceable hearing before surgery), while maintaining tumor control close to $90 \%$.

The article by Troude et al. ${ }^{1}$ is extremely interesting, as it is a large cohort, with longterm follow-up. With the inherent biases described above, most of them being specific to historical cohort studies and to this particular study, it is an important contribution to the current literature. The conclusion that remnant tumors should be observed rather than further treated with GKS, with the evidence they presented, should be carefully interpreted in the context of the approach used and functional results. Further research would ideally need to include randomized control trials, histological analysis and repeated scans for longer period of time, to avoid eventual and inherent biases.

Table 1: current published series with a "nerve-centered approach"

Figure 1: Example of a "nerve-centered approach", with preoperative image (left), MR at the time of GKS (center, with the dosimetry coloured in yellow) and the MR 3 years after GKS (right, with superimposed dosimetry and showing further shrinkage of the tumor) 
Table 1: current published series with a "nerve-centered approach"

\begin{tabular}{|c|c|c|c|c|}
\hline Author (publication year) & Number of patients & $\begin{array}{l}\text { Follow-up } \\
\text { (months) }\end{array}$ & $\begin{array}{c}\text { Facial nerve preservation } \\
(\%)\end{array}$ & Cochle \\
\hline Iwai et al. 5(2003) & 14 & 32 & 85.7 & \\
\hline Park et al. ${ }^{6}(2006)$ & 8 & 68.8 & NA & \\
\hline Yang et al. ${ }^{7}(2008)$ & 61 & 53.7 & 95 & \\
\hline Fuentes et al. ${ }^{8}(2008)$ & 8 & 46 & 87.5 & \\
\hline $\begin{array}{l}\text { Van de Langenberg et al. } \\
{ }^{9}(2011)\end{array}$ & 50 & 33.8 & 94 & \\
\hline Haque et al. ${ }^{10}(2011)$ & 151 & 72 & 97 & \\
\hline Pan et al. ${ }^{11}(2012)$ & 18 & 57 & 89 & \\
\hline Iwai et al. ${ }^{12(2015)}$ & 40 & 66 & 95 & \\
\hline Radwan et al. ${ }^{13(2015)}$ & 22 & 28 & 87 & \\
\hline Monfared et al. ${ }^{14}(2016)$ & 73 & 38 & 81 & \\
\hline Daniel et al. ${ }^{4}(2017)$ & 32 & 29 & 100 & \\
\hline Update of our series & 46 & 36.9 & 100 & \\
\hline
\end{tabular}

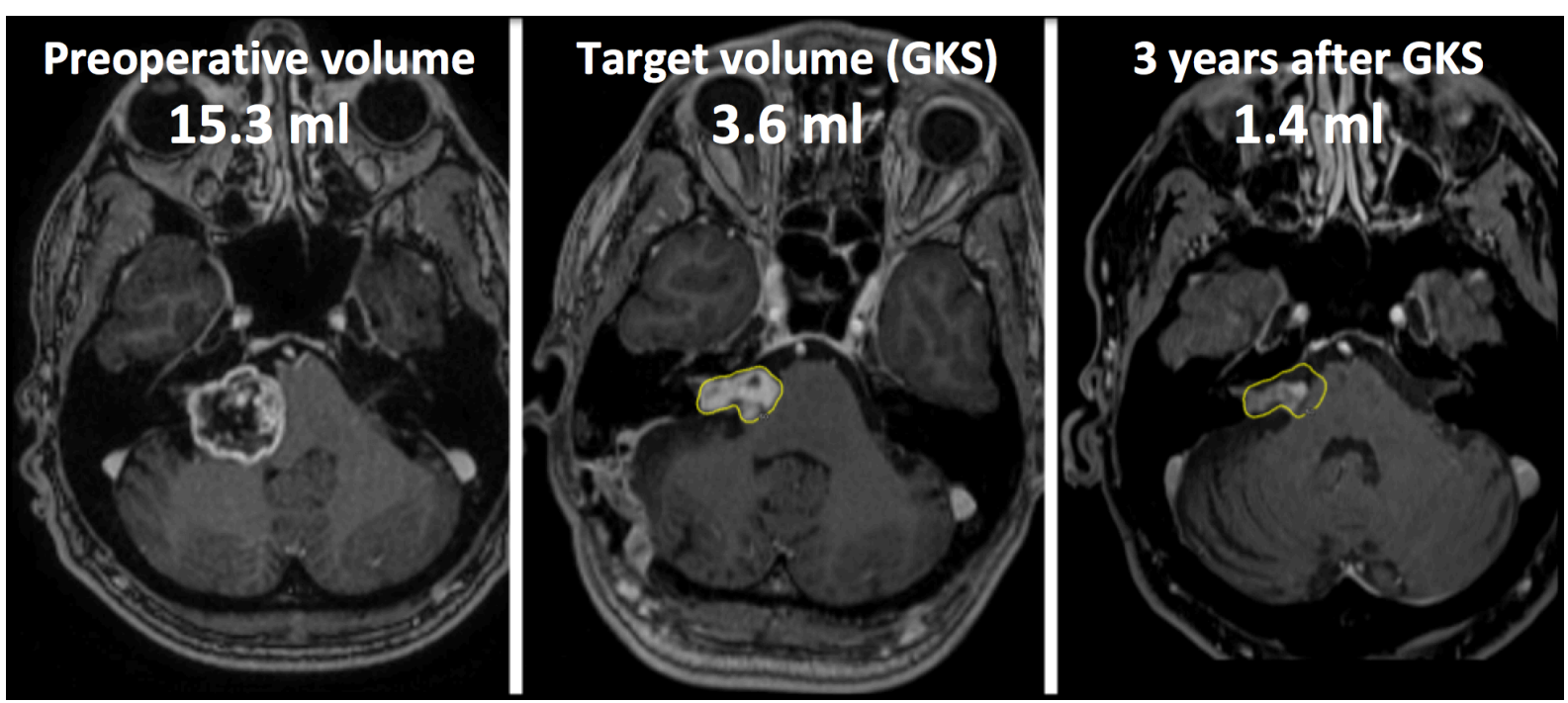




\section{References}

1. Troude L, Boucekine M, Montava M, Lavieille JP, Regis JM, Roche PH. Adjunctive Gamma-Knife Surgery Or Wait \& Scan Policy After Optimal Resection Of Large Vestibular Schwannomas: Clinical And Radiological Outcomes. World neurosurgery. 2018 Jul 18.

2. Starnoni D, Daniel RT, Tuleasca C, George M, Levivier M, Messerer M. Systematic review and meta-analysis of the technique of subtotal resection and stereotactic radiosurgery for large vestibular schwannomas: a "nerve-centered" approach. Neurosurgical focus. 2018 Mar;44(3):E4.

3. Iannella G, de Vincentiis M, Di Gioia C, et al. Subtotal resection of vestibular schwannoma: Evaluation with Ki-67 measurement, magnetic resonance imaging, and long-term observation. The Journal of international medical research. 2017 Jun;45(3):1061-73.

4. Daniel RT, Tuleasca C, George M, et al. Preserving normal facial nerve function and improving hearing outcome in large vestibular schwannomas with a combined approach: planned subtotal resection followed by gamma knife radiosurgery. Acta neurochirurgica. 2017 Jul;159(7):1197-211.

5. Iwai Y, Yamanaka K, Ishiguro T. Surgery combined with radiosurgery of large acoustic neuromas. Surgical neurology. 2003 Apr;59(4):283-9; discussion 9-91.

6. Park CK, Jung HW, Kim JE, Son YJ, Paek SH, Kim DG. Therapeutic strategy for large vestibular schwannomas. Journal of neuro-oncology. 2006 Apr;77(2):167-71.

7. Yang SY, Kim DG, Chung HT, Park SH, Paek SH, Jung HW. Evaluation of tumour response after gamma knife radiosurgery for residual vestibular schwannomas based on MRI morphological features. Journal of neurology, neurosurgery, and psychiatry. 2008 Apr;79(4):431-6.

8. Fuentes S, Arkha Y, Pech-Gourg G, Grisoli F, Dufour H, Regis J. Management of large vestibular schwannomas by combined surgical resection and gamma knife radiosurgery. Progress in neurological surgery. 2008;21:79-82.

9. van de Langenberg R, Hanssens PE, van Overbeeke JJ, et al. Management of large vestibular schwannoma. Part I. Planned subtotal resection followed by Gamma Knife surgery: radiological and clinical aspects. Journal of neurosurgery. 2011 Nov;115(5):875-84.

10. Haque R, Wojtasiewicz TJ, Gigante PR, et al. Efficacy of facial nerve-sparing approach in patients with vestibular schwannomas. Journal of neurosurgery. 2011 Nov;115(5):917-23.

11. Pan HC, Sheehan J, Sheu ML, Chiu WT, Yang DY. Intracapsular decompression or radical resection followed by Gamma Knife surgery for patients harboring a large vestibular schwannoma. Journal of neurosurgery. 2012 Dec;117 Suppl:69-77. 
12. Iwai Y, Ishibashi K, Watanabe $Y$, Uemura G, Yamanaka K. Functional Preservation After Planned Partial Resection Followed by Gamma Knife Radiosurgery for Large Vestibular Schwannomas. World neurosurgery. 2015 Aug;84(2):292-300.

13. Radwan H, Eisenberg MB, Sandberg Knisely JP, Ghaly MM, Schulder M. Outcomes in Patients with Vestibular Schwannoma after Subtotal Resection and Adjuvant Radiosurgery. Stereotactic and functional neurosurgery. 2016;94(4):216-24.

14. Monfared A, Corrales CE, Theodosopoulos PV, et al. Facial Nerve Outcome and Tumor Control Rate as a Function of Degree of Resection in Treatment of Large Acoustic Neuromas: Preliminary Report of the Acoustic Neuroma Subtotal Resection Study (ANSRS). Neurosurgery. 2016 Aug;79(2):194-203. 